\title{
Kernos
}

Revue internationale et pluridisciplinaire de religion grecque antique

$20 \mid 2007$

Varia

\section{HUBER Sandrine, L'aire sacrificielle au nord du sanctuaire d'Apollon Daphnéphoros. Un rituel des époques géométrique et archaïque}

\section{Vinciane Pirenne-Delforge}

\section{OpenEdition}

\section{Journals}

Édition électronique

URL : https://journals.openedition.org/kernos/393

DOI : $10.4000 /$ kernos.393

ISSN : 2034-7871

\section{Éditeur}

Centre international d'étude de la religion grecque antique

\section{Édition imprimée}

Date de publication : 1 janvier 2007

Pagination : 451-452

ISSN : 0776-3824

Référence électronique

Vinciane Pirenne-Delforge, " HUBER Sandrine, L'aire sacrificielle au nord du sanctuaire d'Apollon

Daphnéphoros. Un rituel des époques géométrique et archaïque », Kernos [En ligne], 20 | 2007, mis en ligne le 17 mars 2011, consulté le 08 septembre 2022. URL : http://journals.openedition.org/kernos/ 393 ; DOI : https://doi.org/10.4000/kernos.393 
HUBER Sandrine, L'aire sacrificielle au nord du sanctuaire d'Apollon Daphnéphoros. Un rituel des époques géométrique et archaïque. Vol. I - Texte, avec une contribution de Isabelle Chenal-Velarde et Jacqueline Studer. Vol. II - Catalogues, tableaux et planches, École suisse d'archéologie en Grèce, 2003. 2 vol. $22 \times 30$ cm, 189 p.+82 p. \& 142 planches (Eretria. Fouilles et recherches, 14). ISBN : 2-88474-402-9.

Cet ouvrage soigné est la publication définitive de la fouille menée par l'École archéologique suisse dans l'espace de quelque $40 \mathrm{~m}^{2}$ situé au nord du sanctuaire d'Apollon Daphnéphoros à Érétrie. Cet espace - qui n'a pu être complètement fouillé dans sa partie nord - est conventionnellement appelé «Aire sacrificielle Nord». Le volume I propose, après une introduction qui précise les principes directeurs de la publication, un $1^{\text {er }}$ chapitre qui analyse les structures fouillées et la stratigraphie du site, un $2^{\mathrm{e}}$ chapitre sur le mobilier céramique, un $3^{\mathrm{e}}$ chapitre sur le mobilier non céramique, un $4 \mathrm{e}$ chapitre qui exploite les données archéologiques en recourant à de nombreux parallèles, tandis que le $5^{\mathrm{e}}$ chapitre se penche sur le rituel que permettent de reconstituer ces données, en proposant une identification de la divinité honorée. La conclusion situe cette aire sacrificielle dans le cadre des rituels attestés aux périodes géométrique et archaïque dans le reste du monde grec. Elle cherche aussi à en comprendre le rôle au sein même de la cité d'Érétrie. Une très intéressante annexe archéozoologique referme le livre, annexe dont les conclusions sont interprétées par S. Huber (S.H.) aux chapitres 4 et 5 . Le volume II comprend quant à lui les catalogues, les plans et coupes, ainsi que les reproductions des structures et des objets mis au jour. Le tout est d'une très grande qualité et d'une très grande lisibilité.

Une telle publication montre tout l'intérêt d'une archéologie religieuse rigoureusement menée, selon les impératifs les plus récents de la discipline, sans verser dans deux excès contraires que les historiens de la religion grecque ont à déplorer lorsqu'ils affrontent les rapports de fouilles : le repli frileux sur la simple description ou la surinterprétation à coup de concepts inadéquats. Ces deux excès sont ici soigneusement évités, ce qui nous vaut une remarquable analyse compréhensive de cette « aire sacrificielle » et des rituels qui ont dû s'y dérouler pendant les périodes géométrique et archaïque.

Le statut de cet espace semble bien être celui d'un enclos à ciel ouvert, centré sur une structure construite ronde $\left(\mathrm{n}^{\circ} 45\right)$ que S.H. interprète comme un autel. Quant à savoir s'il faisait partie de l'ensemble plus vaste du sanctuaire d'Apollon Daphnéphoros ou s'il en était indépendant, sans trancher de façon définitive, c'est la première solution qui est la plus vraisemblable, même si la présence originelle d'un cours d'eau entre l'aire sacrificielle et le cœur du sanctuaire d'Apollon peut orienter vers la deuxième option. Le site a été tellement perturbé qu'il est difficile de conclure avec certitude à l'absence de structure construite dans la zone. Quoi qu'il en soit, ce sont les objets mis au jour autour de la structure cylindrique 45 et dans son remplissage qui permettent d'appréhender les gestes posés dans ce cadre religieux. Le remplissage était constitué de céramique grossière, d'hydries et de cendres, le tout daté entre VIII et $\mathrm{VIII}^{\mathrm{e}} \mathrm{s}$. Autour de la structure, ce sont des dépôts d'offrandes successifs, étalés ou jetés dans des fosses qui constituent le matériel disponible. Or ce mobilier présente des caractéristiques spécifiques qui se distinguent des trouvailles effectuées dans le sanctuaire voisin. La céramique est majoritaire et se divise en deux grands types de vases : les hydries miniatures, d'une part, les cruches à haut col parfois décorées, d'autre part. L'interaction entre matériel votif et liturgique est bien mise en évidence : un vase utilisé lors d'un rituel et laissé sur place - entier ou intentionnellement brisé - était « dédié » par sa déposition même. Le reste des objets mis au jour (pièces de parures, quelques chaudrons miniatures et pointes de flèches, amulettes, sceaux et scarabées en grand nombre, statuettes en nombre très réduit) serait le fait de dédicaces personnelles. Parmi ces objets, on trouve des 
instruments liés au travail du textile, qui semblent bien faire le lien avec l'iconographie des cruches à haut col dont l'interprétation constitue le cœur du propos. Les quelques vases décorés mis au jour ne présentent que des figures féminines. Quelques images semblent se référer à une procession de femmes portant des couronnes. D'autres montrent deux femmes de part et d'autre d'un objet. Il peut s'agir d'un arbre. Dans un autre cas, il pourrait s'agir d'un autel surmonté d'une grille (mais elle est représentée verticalement). Enfin, le cas le plus intéressant (V 41) est interprété par S.H. comme une étoffe encore tendue sur un métier à tisser, qui pourrait renvoyer à un rituel du type " péplophorie ». Quoi qu’il en soit, la tonalité qui se dégage à la fois des objets dédiés et de l'iconographie est essentiellement féminine. La quantité impressionnante d'hydries pointe évidemment vers un rituel lié à l'eau, que la présence sans doute obsédante et problématique du cours d'eau voisin ne fait que confirmer. Enfin, l'analyse ostéologique met en évidence une écrasante majorité de fémurs de caprinés calcinés. L’archéozoologie appliquée à l'aire sacrificielle d'Érétrie illustre la procédure "prométhéenne » : ce sont les cuisses (os seuls ? encore garnis de viande ?) de chèvres et/ou de moutons qui sont bel et bien offertes à la divinité.

Lorsqu'on les compare aux données du sanctuaire d'Apollon (parties animales consommées, cratères, dédicaces « civiques »), les trouvailles de l'aire sacrificielle s'inscrivent dans un jeu d'opposition presque trop parfait! Il n'en reste pas moins que l'identification de la divinité honorée avec Artémis a pour elle de très bon arguments, parmi lesquels cette opposition «masculin/féminin» n'est pas tout. S.H. déploie de larges comparaisons et fait appel à tout ce que l'on sait de la vie religieuse érétrienne pour asseoir son interprétation très vraisemblable. Il n'en reste pas moins qu'il faut résister à la tentation de transformer une hypothèse vraisemblable en certitude (ce que la conclusion tend à faire). Après tout, avec de très bons arguments elle aussi, Susan Guettel Cole interprétait l'aire sacrificielle comme l'ancêtre du Thesmophorion de l'acropole: pour elle, on y honorait donc Déméter ${ }^{1}$. En l'absence d'inscription, il faut reconnaitre que l'identification d'un destinataire divin est toujours une gageure! Mais le pari devait être fait et il l'est de très belle manière.

Vinciane Pirenne-Delforge (FNRS - Université de Liège)

OSAnNA Massimo, SICA M. Maddalena (éds), Torre di Satriano I. Il santuario lucano, Osanna Edizione, 2005. 1 vol. $21 \times 28 \mathrm{~cm}, 495$ p. (Deputazione di Storia patria per la Lucania. Quaderni Archeologici. Università degli studi della Basilicata. Scuola di specializzazione in archeologia di Matera, 11). ISBN : 88-8167-249-9.

Cet important volume est le premier rapport de fouille du sanctuaire lucanien de Torre di Satriano exploré par l'équipe de l'Università degli Studi della Basilicata entre 2000 et 2003. Il complète une première étude parue en 2001 à l'occasion de l'exposition Rituali per una dea lucana. Il santuario di Torre di Satriano éditée par M. L. Nava et M. Osanna (cf. recension dans Kernos 15, 2002, p. 530-532). Le présent ouvrage comprend quatre parties consacrées respectivement au territoire lucanien depuis l'époque archaïque jusqu’à la romanisation (I), à l'histoire des fouilles et aux structures du complexe sacré (II), au matériel céramique, métallique et coroplastique (III) ainsi qu'aux aspects rituels du culte de ce sanctuaire (IV). Viennent ensuite cinq appendices dans lesquels le lecteur trouvera l'étude de deux documents épigraphiques (I), les résultats des sondages géomorphologiques (II), une synthèse sur les méthodes d’investigation (III), les analyses archéométriques (IV) et archéozoologiques (V).

${ }^{1}$ S. Guettel Cole, «Demeter in City and Countryside », in S.E. Alcock, R. Osborne (éds), Placing the Gods. Sanctuaries and Sacred Space in Ancient Greece, Oxford, 1994, p. 207-208. 